\title{
Eponymous women in ophthalmology: syndromes with prominent eye manifestations named after female physicians
}

\author{
Sarah H. Van Tassel ${ }^{1} \cdot$ Kira L. Segal $^{1,2} \cdot$ Jessica B. Ciralsky $^{1} \cdot$ Grace Sun $^{1}$ \\ Received: 18 March 2018 / Accepted: 3 April 2018 / Published online: 14 May 2018 \\ (c) The Royal College of Ophthalmologists 2018
}

Many eponymic syndromes were characterized when few women had entered medicine. Nearly simultaneous with the growth of women in ophthalmology has been a decreased emphasis on eponyms in favor of descriptive $[1,2]$ or biochemical [2-4] terminology. The decline in eponym use has been fueled by calls to eliminate the possessive form [2], concerns regarding inaccuracy as knowledge of disease pathogenesis has evolved [3, 4], worries that using different eponyms across languages stymies global scientific discussion [1], and the realization of inhumane activities by some individuals to whom eponyms were previously attributed [1,3]. Nonetheless, it is of important historical relevance to identify and celebrate the women who distinguished themselves by helping to characterize syndromes associated with their names.

For this report, we culled print and electronic media for eponymous eye syndromes named after female ophthalmologists. Public records, obituaries, images, and other resources were compared to determine gender. Only syndromes listed in OMIM were reviewed to avoid inclusion of arcane eponyms. Syndromes in which the only ophthalmicrelated features are craniofacial abnormalities, optic atrophy, and/or cortical blindness were excluded in order to focus inclusion on eye-related syndromes.

Two eponymous female ophthalmologists were identified: Ester Elisabeth Gröenblad and Mette Warburg.

Sarah H. Van Tassel

sjh2006@med.cornell.edu

1 Department of Ophthalmology, Weill Cornell Medicine, 1305 York Avenue, 11th Floor, New York, NY 10021, USA

2 Kellogg Eye Center, Department of Ophthalmology and Visual Sciences, University of Michigan Health System, Ann Arbor, MI 48105, USA
Gröenblad-Strandberg disease is pseudoxanthoma elasticum (PXE), characterized by ectopic mineralization and fragmentation of elastic fibers primarily in the eye, skin, and cardiovascular system. Ophthalmic findings include angioid streaks, peau d'orange fundus, and choroidal neovascularization. Gröenblad, a Swedish ophthalmologist, established the syndromic association of angioid streaks with the skin findings in collaboration with dermatologist James Strandberg.

Walker-Warburg syndrome causes brain abnormalities and retinal dysplasia. Neurosurgeon Arthur Earl Walker reported a case of hydrocephalus, lissencephaly, microphthalmos, and retinal dysplasia in 1942; additional authors subsequently presented cases. Warburg, a Danish ophthalmologist, suggested in 1971 that the findings represented a yet-uncharacterized syndrome. Today, the syndrome is referred to as muscular dystrophy-dystroglycanopathy with brain and eye anomalies, and genetic sequencing has led to subtype classification.

During our search for eponymous ophthalmologists, we identified several female non-ophthalmologist physicians who characterized syndromes with prominent eye manifestations (Table 1).

As is common among eponyms, the syndromes identified herein were not all named after the original discoverers, a phenomenon described as Stigler's Law of Eponymy [5]. The skin and eye findings of PXE had been described before Gröenblad and Strandberg established the syndromic association. Cases of Walker-Warburg syndrome were reported by Walker and others as many as 30 years prior to Warburg's papers, but eponymous credit is given to her due to her summative assessments of the syndrome. Warburg also described Norrie syndrome but named it in tribute after Gordon Norrie, a Danish ophthalmologist.

The plethora of historical eponyms leaves open the possibility that our report is incomplete. Additionally, binary gender categories may unintentionally exclude or mischaracterize some individuals. 


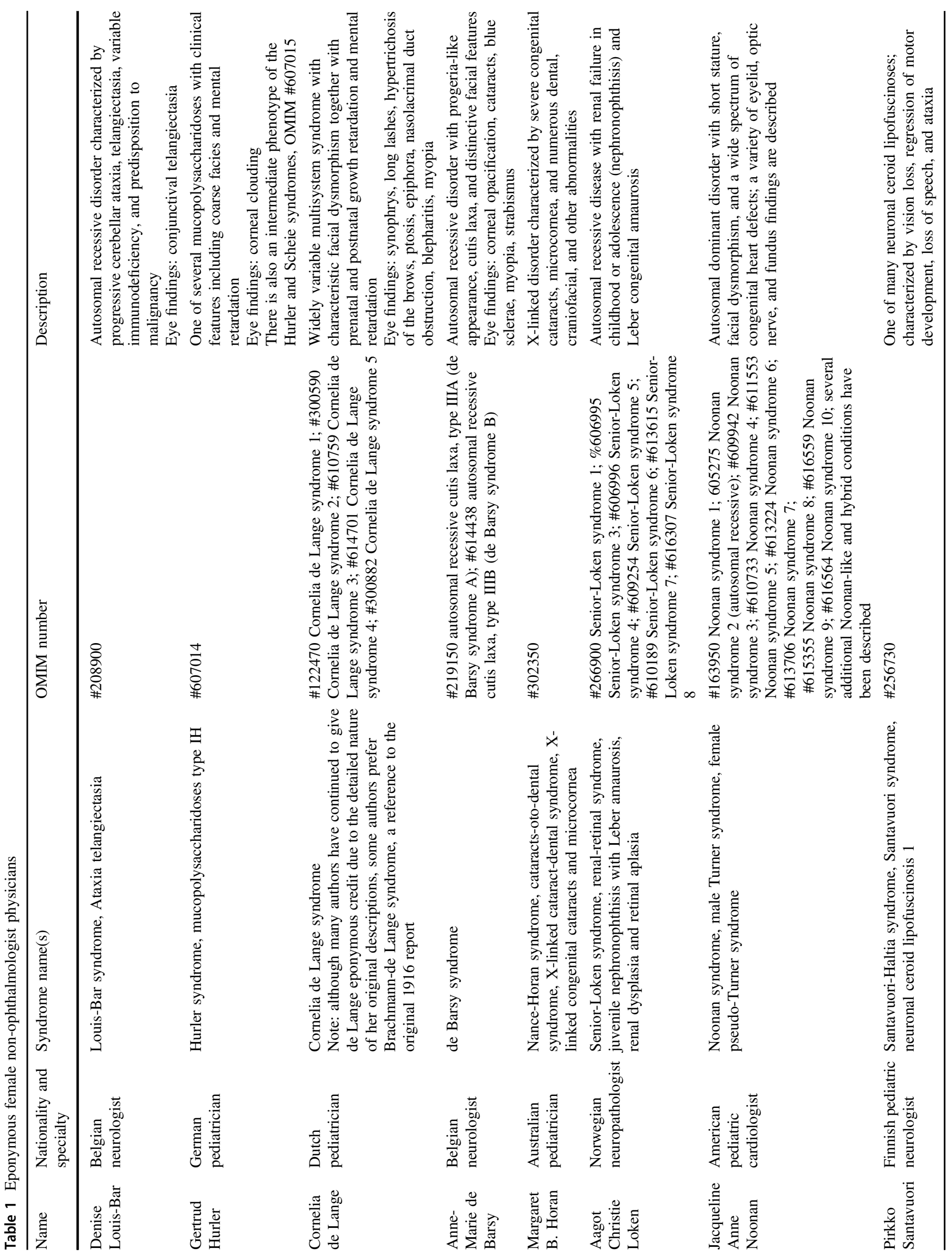


To our knowledge, this is the first report of syndromes with prominent eye manifestations named after female physicians. Eponyms embed history and tradition into our shared medical language, and identifying eponymous women has historical relevance and celebrates their achievements.

\section{Compliance with ethical standards}

Conflict of interest The authors declare that they have no conflict of interest.

\section{References}

1. Woywodt A, Matteson E. Should eponyms be abandoned? Yes. Br Med J. 2007;335:424.

2. Smith WD. Classification, nomenclature, and naming of morphologic defects. J Pediatr. 1975;87:162-3.

3. Pulido JS, Matteson EL. Eponyms: what's in a name? Retina. 2010;30:1559-60.

4. Cogan DG. The rise and fall of eponyms. Arch Ophthalmol. 1978;96:2202-3.

5. Stigler SM. Stigler's law of eponymy. Trans NY Acad Sci. 1980;39:147-57. 